\title{
Publisher Correction to: Comparison between AirQ+ and BenMAP-CE in estimating the health benefits of $\mathrm{PM}_{2.5}$ reduction
}

\author{
Asma Mirzaei ${ }^{1} \cdot$ Hannaneh Tahriri ${ }^{1} \cdot$ Babak Khorsandi ${ }^{1}$ (i)
}

Accepted: 24 June 2021 / Published online: 8 July 2021

(c) Springer Nature B.V. 2021

Publisher Correction to: Air Quality, Atmosphere \& Health (2021) 14:807-815 https://doi.org/10.1007/s11869-021-00980-5

The original version of the article unfortunately contains a mistake introduced during the production phase. The equation found in page 809 is incorrect. Also, the "I and N" of the equation found in page 810 should be italicized. The correct presentation of these equations are given below.

$\mathrm{AP}=\frac{\sum\{[\mathrm{RR}(c)-1] \times P(c)\}}{\sum[\mathrm{RR}(c) \times P(c)]}$

$\Delta \mathrm{Y}=I \times N \times\left(1-\exp ^{-\beta \times \Delta \mathrm{PM}}\right)$
The original article has been corrected.

Publisher's note Springer Nature remains neutral with regard to jurisdictional claims in published maps and institutional affiliations.

The original article can be found online at https://doi.org/10.1007/ s11869-021-00980-5.

Babak Khorsandi

b.khorsandi@aut.ac.ir

1 Department of Civil and Environmental Engineering, Amirkabir University of Technology (Tehran Polytechnic), Tehran, Iran 